\title{
Altered sodium currents in auditory neurons of congenitally deaf mice
}

\author{
Richardson N. Leão, Marcell M. Naves, Katarina E. Leão and Bruce Walmsley \\ Synapse and Hearing Laboratory, Division of Neuroscience, John Curtin School of Medical Research, Australian National \\ University, PO Box 334, Canberra, ACT 0200, Australia
}

Keywords: auditory, deafness, Nav1.6, sodium currents

\begin{abstract}
Sodium currents are essential for action potential generation and propagation in most excitable cells. Appropriate tuning of these currents can be modulated both developmentally and in response to activity. Here we use a mouse model of congenital deafness ( $d n / d n$ - asymptomatic deafness associated with hair cell degeneration) to investigate the effect of lack of activity in the expression of $\mathrm{Na}^{+}$currents in neurons from the medial nucleus of the trapezoid body (MNTB). Patch-clamp recordings show that at postnatal day (P) 14, both normal and deaf mice display a significant amount of persistent and resurgent $\mathrm{Na}^{+}$currents. However, the persistent current is greater in deaf mice than in normal mice, and resurgent current kinetics are slower in deaf mice. At P7, resurgent currents are not present in either group. MNTB immunohistochemistry demonstrates that Nav1.1 subunits are expressed postsynaptically in both P14 normal and deaf mice, while postsynaptic Nav1.6 staining was only observed in deaf mice. Labelling of Nav1.6 subunits in different age groups revealed that at younger ages (P7), both normal and deaf mice express this protein. Nav1.6 staining was not observed in MNTB neurons of P28 normal mice, whereas it is maintained in deaf mice cells until much later (P28). At P7, none of the groups displayed resurgent currents (despite the detection of Nav1.6 subunits at this age group); this suggests that factors other than alpha subunits are important for modulating these currents in MNTB cells. Our results emphasize the importance of activity during development in regulating $\mathrm{Na}^{+}$channels.
\end{abstract}

\section{Introduction}

In terms of fidelity, the medial nucleus of the trapezoid body (MNTB) is one of the most remarkable nuclei in the auditory nervous system. MNTB neurons have unique pre- and postsynaptic specializations that help the MNTB preserve information fidelity at high firing frequencies. Presynaptically, the largest synaptic terminal in the mammal central nervous system, the calyx of Held, generates large-amplitude excitatory postsynaptic currents (EPSCs) at frequencies up to $800 \mathrm{~Hz}$ while MNTB principal neurons can respond to such frequencies by maintaining a small membrane time constant and rapidly repolarizing the membrane following the peak of the action potential (AP) by opening high-threshold $\mathrm{K}^{+}$channels. Potassium currents in MNTB cells have been extensively studied in recent years and are well characterized. However, few studies have investigated postsynaptic MNTB Na ${ }^{+}$currents (but see Ming \& Wang, 2003; Leao et al., 2005a).

One of the most comprehensive descriptions of $\mathrm{Na}^{+}$currents in the superior olivary complex is found in a recent study by Leao et al. (2005a), who described in detail tetrodotoxin (TTX)-sensitive currents in the calyx of Held. These authors also investigated, less extensively, $\mathrm{Na}^{+}$currents postsynaptically in the principal cell. Presynaptic $\mathrm{Na}^{+}$ channels are gradually distributed along the axon preceding the calyx of Held, with a higher density distally and less proximally to the calyceal terminal. Sodium currents at the calyx of Held are also singular. They recover from inactivation extremely rapidly as

Correspondence: Dr R. N. Leão, as above.

E-mail: Richardson.Leao@anu.edu.au

Received 16 March 2006, revised 1 June 2006, accepted 1 June 2006 compared with $\mathrm{Na}^{+}$currents elsewhere (Leao et al., 2005a). Sodium currents in postsynaptic MNTB neurons do not display the same characteristics as in the presynaptic terminal. However, the presence of $\mathrm{Na}^{+}$channels in the postsynaptic cell soma (or in its vicinity) is intriguing, as following large calyceal EPSPs, one would expect rapid inactivation of somatic $\mathrm{Na}^{+}$channels. Characterization of TTXsensitive channels is complex, as different $\mathrm{Na}^{+}$channel subtypes show similar kinetics, and appropriate current recordings are difficult to obtain owing to 'space-clamp' problems of fast and large currents. Activation $V_{1 / 2}$, for example, for expressed Nav1.1, Nav1.2 and Nav1.6 channel subtypes differ by less than $1 \mathrm{mV}$ (Smith et al., 1998; Herzog et al., 2003). However, the assessment of postsynaptic $\mathrm{Na}^{+}$ currents is crucial to the understanding of MNTB function in this auditory pathway. Moreover, it is unclear how development and activity influence $\mathrm{Na}^{+}$currents in the MNTB. It has been reported in other systems that development and pathologies alter the expression of $\mathrm{Na}^{+}$channels (Craner et al., 2003; Rasband et al., 2003). Development, for example, modulates the migration of Nav1.6 (found in cell somas in immature neurons) from the soma to nodes of Ranvier (Suzuki et al., 2004). Abnormal activity in sensory neurons (caused, for example, by peripheral nerve injury) alters the expression of voltage-gated $\mathrm{Na}^{+}$channels (Pertin et al., 2005). One valuable model of lack of sensory activity on the auditory nervous system is the $d n / d n$ mouse (Keats et al., 1995; Leao et al., 2005). These mice suffer from asymptomatic congenital deafness and display no evoked spontaneous activity from the cochlea (Keats et al., 1995; Leao et al., 2006). Voltage-dependent $\mathrm{K}^{+}$currents and hyperpolarizing-activated currents are known to be altered in MNTB neurons of $d n / d n$ mice 
(Leao et al., 2004, 2005b, 2006). The effect of deafness on $\mathrm{Na}^{+}$ currents of auditory neurons has not been reported. Here, we investigate TTX-sensitive $\mathrm{Na}^{+}$currents in MNTB cells of normal and $d n / d n$ (deaf) mice using electrophysiological and immunolabelling techniques. We demonstrate that, in deaf mice, there are significant amounts of persistent $\mathrm{Na}^{+}$currents, whereas resurgent $\mathrm{Na}^{+}$currents display slower inactivation kinetics than currents in normal mice. These currents may contribute to different firing patterns observed in neurons of deaf mice.

\section{Methods}

Normal [CBA, postnatal (P) day 7 and 14] and congenitally deaf ( $d n / d n$ with CBA background, P7 and P14) mice were decapitated without anaesthetic according to the Australian National University Animal Ethics Committee protocol. The brainstem and cerebellum were removed and placed in ice-cold hypertonic sucrose solution (in mM: $3 \mathrm{KCl}, 5 \mathrm{MgCl}_{2}, 1 \mathrm{CaCl}_{2}, 1.25 \mathrm{NaH}_{2} \mathrm{PO}_{4}, 26.2 \mathrm{NaHCO}_{3}, 5$ $\mathrm{MgCl}_{2}, 10$ glucose and 218 sucrose). The cerebellum/brainstem block was fixed to the stage of a vibrating tissue slicer (OS-4000, EMF or Integraslicer, Camden Instruments). Tissue blocks in hypertonic sucrose solution were constantly bubbled with 'carbogen' $\left(95 \% \mathrm{O}_{2}\right.$, $\left.5 \% \mathrm{CO}_{2}\right)$ and transverse slices $(150-200 \mu \mathrm{m})$ of the MNTB were made. Slices were then transferred to a chamber containing ACSF (in mM: $130 \mathrm{NaCl}, 3 \mathrm{KCl}, 5 \mathrm{MgCl}_{2}, 1 \mathrm{CaCl}_{2}, 1.25 \mathrm{NaH}_{2} \mathrm{PO}_{4}, 26.2$ $\mathrm{NaHCO}_{3}, 10$ glucose) and incubated for $1 \mathrm{~h}$ at $35{ }^{\circ} \mathrm{C}$ and subsequently held at room temperature $\left(22-25^{\circ} \mathrm{C}\right)$ for electrophysiological recording. All solutions were constantly bubbled with carbogen. Patch-clamp electrodes were pulled in a two-stage electrode puller (Narashige, Japan) and usually had a tip resistance of 1.5-2.5 M 2 . Electrodes were filled with 'internal' solutions based on $\mathrm{CsCl}$ (in $\mathrm{mM}$ : $120 \mathrm{CsCl}, 4 \mathrm{NaCl}, 4 \mathrm{MgCl}_{2}, 0.001 \mathrm{CaCl}_{2}, 10 \mathrm{HEPES}, 3 \mathrm{Mg}$-ATP, 0.3 GTP-Tris and 10 EGTA) or K-gluconate (in mM: $17.5 \mathrm{KCl}, 122.5$ K-gluconate, $9 \mathrm{NaCl}, 1 \mathrm{MgCl}_{2}, 1 \mathrm{HEPES}$ and $0.2 \mathrm{EGTA}$ ); $\mathrm{pH}$ was adjusted to 7.2 using $\mathrm{CsOH}$ or $\mathrm{KOH}$, respectively, and when necessary, osmolarity was adjusted to 290-300 mOsm with sorbitol. All voltage-clamp experiments were performed using pipettes filled with CsCl-based internal solution while K-gluconate-based internal solution was used in all current-clamp experiments. Whole-cell current-clamp and voltage-clamp recordings were made from visualized MNTB neurons using a DIC microscope (Olympus, Japan). Voltage-clamp recordings $\left(\mathrm{Na}^{+}\right.$currents) were performed using the CsCl-based internal solution and current-clamp recordings were made using an internal solution based on K-gluconate. In order to improve 'clamping' of fast $\mathrm{Na}^{+}$currents, superficial MNTB cells were lifted by approximately $15-30 \mu \mathrm{m}$ from the slice with a large borosilicate glass pipette on a second manipulator using a small negative pressure. This manoeuvre separates most of the axon and dendrite(s) from the cell soma. We did not dissociate MNTB neurons in order to preserve information regarding cell locations within the nucleus, as voltagegated channels are known to be differently expressed at different locations within the MNTB (von Hehn et al., 2004; Brew \& Forsythe, 2005; Leao et al., 2006). All currents shown in this work are a result of the digital subtraction of currents recorded before and after the addition of $1 \mu \mathrm{M}$ TTX. We have also simulated resurgent/persistent $\mathrm{Na}^{+}$currents in normal mice neurons using a dynamic clamp. Our method is implemented on a second computer running real-time Linux and custom-made software that reads voltage and generates currents at $40 \mathrm{kHz}$. A description of the dynamic clamp technique can be found in Leao et al. (2005b). Data were digitized using Axograph X (Axon, USA) and analysed using Matlab (Mathworks, USA).

\section{Electrophysiology protocols}

All voltage-clamp protocols were preceded by a $-100-\mathrm{mV}, 500-\mathrm{ms}$ pretest voltage. Voltage-clamp protocols used in this study consisted of: (1) $10-\mathrm{ms}$ voltage steps ranging from -83 to $53 \mathrm{mV}$ in $8-\mathrm{mV}$ increments or -60 to $10 \mathrm{mV}$ in $5-\mathrm{mV}$ steps (used to assess fastinactivating $\mathrm{Na}^{+}$currents); (2) $-40-\mathrm{mV}$ voltage steps of various durations (0-18 ms, -2-ms increment) and a 100-ms, 0-mV step (development of inactivation); (3) 25-ms, $0-\mathrm{mV}$ voltage steps followed by $-50-\mathrm{mV}$ voltage steps with varying duration $(1-14.5 \mathrm{~ms}, 1.5-\mathrm{ms}$ increment - recovery from inactivation); (4) $10-\mathrm{ms} 30-\mathrm{mV}$ voltage steps followed by $100-\mathrm{ms}$ voltage steps of amplitudes varying from -75 to $-30 \mathrm{mV}$ in $5-\mathrm{mV}$ increments (resurgent $\mathrm{Na}^{+}$currents). Current clamp protocols consisted of 200-ms current steps from -50 to $400 \mathrm{pA}$ and current pulses $(1.5 \mathrm{nA}, 0.5 \mathrm{~ms})$ at different frequencies $(200-300 \mathrm{~Hz})$. Data are presented as means \pm SEM, statistical significance was tested using an unpaired $t$ (Student's)-test and paired $t$-test (for paired data) and differences between means were considered significant at $P=0.05$.

\section{Dynamic clamp equations}

In order to assess the functional effects of anomalous $\mathrm{Na}^{+}$currents in MNTB neurons, we have fitted time constants vs. voltage and current vs. voltage relationships of slow deaf mice resurgent/persistent $\mathrm{Na}^{+}$ currents subtracted from the normal mice resurgent currents according to experimental data. The model consisted of activation and inactivation evolution variables ( $a$ and $b$, respectively) and the currents were calculated from $I_{\mathrm{Nar}}=a b\left(V-V_{\mathrm{Na}}\right)$, where $V$ is the membrane voltage and $V_{\mathrm{Na}}$ is the sodium reversal voltage. Evolution variables were solved by the following equation:

$$
\frac{\mathrm{d} x}{\mathrm{~d} t}=\frac{x_{\infty}-x}{\tau_{x}}, x=a, b
$$

Activation time constant vs. voltage and current vs. voltage (Boltzmann) functions were:

$$
\begin{gathered}
\tau_{a}(V)=\frac{5.16}{3.41 \mathrm{e}^{0.1397(V+45.93)}} \times 103.82 \mathrm{e}^{-1.5152(V+45.93)}+0.6 \\
a_{\infty}(V)=\left(1+\mathrm{e}^{-0.2469(V+36.91)}\right)^{-1}
\end{gathered}
$$

and inactivation functions were:

$$
\begin{gathered}
\tau_{b}(V)=\frac{71.64}{1+\mathrm{e}^{0.5291(V+84.3)}}+1.54 \\
b_{\infty}(V)=\left(1+\mathrm{e}^{0.3436(V+40.13)}\right)^{-1}
\end{gathered}
$$

\section{Immunohistochemistry}

Immunohistochemistry was used to assess differences in subunit composition of voltage-dependent $\mathrm{Na}^{+}$channels in MNTB neurons of 
normal and deaf mice. MNTB slices for immunohistochemistry were obtained using the same technique as the electrophysiology slicing. From the slicer chamber, MNTB sections were transferred to a fixing solution of $4 \%$ paraformaldehyde in PBS (17.52 $\mathrm{g} \mathrm{NaCl}, 0.4 \mathrm{~g} \mathrm{KCl}$, $100 \mathrm{~mL}$ of $0.2 \mathrm{M}$ phosphate buffer, $1.9 \mathrm{~L}$ distilled water) for $1 \mathrm{~h}$. Sections were washed in PBS and then kept in PBS plus $0.1 \%$ Triton (PBS-T) overnight. Slices were blocked using normal donkey serum (1 : 10 PBS-T) for $30 \mathrm{~min}$. Primary antibodies for the voltagedependent $\mathrm{Na}^{+}$channels Nav1.1, Nav1.2 or Nav1.6 (raised in rabbit; $1: 100$ PBS-T - Alomone Laboratories) were applied to the slices and left overnight under constant agitation at room temperature. Sections were then washed in PBS-T for $20 \mathrm{~min}$. Secondary antibodies (Vector) with the 'biotin link' were applied to the sections for $4 \mathrm{~h}$ under agitation (for biotinylated linked staining). Finally, the sections were washed and left in the avidin-biotin conjugate (ABC, Vector) for $1 \mathrm{~h}$, washed in PBS-T and left for $30 \mathrm{~min}$ in DAB solution $(0.02 \mathrm{~g}$ diaminobenzidine, $100 \mathrm{~mL}$ Tris, $33 \mu \mathrm{L}$ hydrogen peroxidase). Sections were then washed and mounted on glass slides for microscopy. In order to investigate possible developmental changes in $\mathrm{Na}^{+}$-channel subtype, we also used younger and older normal and deaf mice (P7 and P28) for the Nav labelling studies. Comparisons are shown only for tissue processed in the same batch and photographed under the same light intensity. When comparisons were necessary, small defined areas of interest (AOIs) were drawn manually to incorporate individual cell outlines or, separately, the presynaptic profiles immediately surrounding each cell. The average optical density (OD) of labelling in the respective AOIs was measured automatically using MCID 7.0 (Imaging Research Inc., UK) or Matlab. OD ' $n$ ' values refer to the number of sections from different animals.

\section{Results}

Voltage-clamp recordings were obtained for $140 \mathrm{MNTB}$ cells from 14day-old normal and deaf mice, However, in only 40 cells could $\mathrm{Na}^{+}$ currents be reasonably 'clamped'. In 20 of these cells, a second manipulator was used to 'lift' the cell from the slice prior to the recording (see Methods). In general, MNTB neurons in which $\mathrm{Na}^{+}$ currents were recorded had smaller capacitance than the average observed in MNTB cells - normal mice cells: $17 \pm 0.5$ vs. $18.9 \pm 0.7 \mathrm{pF}(n=70, P<0.05)$; deaf mice cells: $17.6 \pm 0.5$ vs. $18.5 \pm 1 \mathrm{pF}$ ( $n=70$, not significant). There was no difference in cell capacitance and input resistance between normal and deaf mice MNTB neurons.

\section{$\mathrm{Na}^{+}$currents in neurons of normal and deaf mice display similar amplitudes, and activation and fast inactivation kinetics}

In order to isolate inactivating $\mathrm{Na}^{+}$currents, recordings were performed in ACSF containing $100 \mu \mathrm{M} \mathrm{CdCl} 2$ (to block $\mathrm{Ca}^{2+}$ currents), $3 \mathrm{mM}$ TEA and $200 \mu \mathrm{M} \mathrm{BaCl}{ }_{2}$ (to block inward rectifier currents) with or without $1 \mu \mathrm{M}$ TTX. TTX-sensitive $\mathrm{Na}^{+}$currents were isolated by applying 30-ms current steps of various voltage amplitudes after a 500-ms, $-100-\mathrm{mV}$ voltage step before and after $1 \mu \mathrm{M}$ TTX application. TTX-sensitive $\mathrm{Na}^{+}$currents had similar amplitudes and activation kinetics in normal and deaf mice (Fig. 1A). Peak $\mathrm{Na}^{+}$ currents at $-27 \mathrm{mV}$ were $-4.8 \pm 0.5$ and $-5.2 \pm 0.8 \mathrm{nA}$ in normal and deaf mice, respectively $(n=32$; Fig. 1A). Inactivation time constants were also fitted with a double exponential (Fig. 1B). No significant differences were found between fast inactivation time constants $\left(\tau_{\text {Fast }}-0.4 \pm 0.02 \mathrm{~ms}\right.$ in normal mice and $0.5 \pm 0.1 \mathrm{~ms}$ in deaf mice, $n=32$ ) in neurons of normal and deaf mice; however, slow inactivation time constants $\left(\tau_{\text {Slow }}\right)$ were significantly slower in neurons of deaf mice than those of normal mice $(7 \pm 0.5$ vs. $10 \pm 0.8 \mathrm{~ms}$, respectively, $n=32, P<0.04$; Fig. 1B). In order to improve the 'space-clamp', we also used low-sodium ACSF (by exchanging $\mathrm{NaCl}$ with $\mathrm{CsCl}$ on an equimolar basis). Activation time constants (obtained in $60 \mathrm{mM} \mathrm{Na}^{+}$ACSF) for normal and deaf mice at $-25 \mathrm{mV}$ were, respectively, $0.42 \pm 0.12$ and $0.43 \pm 0.1 \mathrm{~ms}(n=8)$. Similar to the results observed in normal $\mathrm{Na}^{+}$ACSF, there was no difference in $\tau_{\text {Fast }}$ between normal and deaf mice in low- $\mathrm{Na}^{+} \mathrm{ACSF}$, but $\tau_{\text {Slow }}$ was significantly different $(6.5 \pm 0.4 \mathrm{~ms}$ in normal mice and $11 \pm 0.6 \mathrm{~ms}$ in deaf mice, $P<0.04, n=8)$. Normalized TTXsensitive $\mathrm{Na}^{+}$currents (measured in $60 \mathrm{mM}$ ACSF) vs. voltage relationships did not differ between normal and deaf mice (Fig. 1C and D). Development of $\mathrm{Na}^{+}$current inactivation was investigated by raising the membrane potential from $-100 \mathrm{mV}$ to $-40 \mathrm{mV}$ and $\mathrm{Na}^{+}$ currents were elicited using a $0 \mathrm{mV}$ step. Development of inactivation occurred faster in normal mice than deaf mice cells. Maintaining the membrane potential at $-40 \mathrm{mV}$ for $18 \mathrm{~ms}$ before the test pulse $(0 \mathrm{mV})$ caused a depression in TTX-sensitive $\mathrm{Na}^{+}$currents by $58 \pm 2 \%$ in normal mice neurons and $31 \pm 5 \%$ in deaf mice cells $(n=20$, $P<0.02$; Fig. $1 \mathrm{E}$ and F). Recovery from inactivation of TTXsensitive $\mathrm{Na}^{+}$currents did not differ between normal and deaf mice. To recover $\mathrm{Na}^{+}$currents partially after $0 \mathrm{mV}$ steps, $-50 \mathrm{mV}$ voltage steps of several durations followed by another $0 \mathrm{mV}$ were applied to the cell. Step duration of $14.5 \mathrm{~ms}$ recovered $29 \pm 3 \%$ in normal mice and $26 \pm 4 \%$ in deaf mice ( $n=20$; Fig. $1 \mathrm{E}$ and F). Both normal and deaf mice $\mathrm{Na}^{+}$currents in neurons recovered completely after $100-\mathrm{ms} /-80$ $\mathrm{mV}$ voltage steps. We also recorded from outside-out patches from both normal and deaf mice MNTB cells in order to confirm the presence of $\mathrm{Na}^{+}$channels in somatic membranes of MNTB neurons. In both groups, small, but sizable, $\mathrm{Na}^{+}$currents (sensitive to $1 \mu \mathrm{M}$ TTX) were observed (at $-27 \mathrm{mV},-153 \pm 47$ and $-160 \pm 40 \mathrm{pA}$ in normal and deaf mice, respectively, $n=8, P>0.05$; see Supplementary material, Fig. S1). Only one outside-out patch from a deaf mouse cell showed a persistent $\mathrm{Na}^{+}$current (see Supplementary material, Fig. S1). The lack of persistent currents in outside-out patches could either be caused by a heterogeneous population of $\mathrm{Na}^{+}$channels on the patches, amplifier limitations or phosphorylation of $\mathrm{Na}^{+}$channels (Grieco et al., 2002).

\section{$\mathrm{Na}^{+}$currents in neurons of deaf mice show a larger persistent component compared with normal mice}

Both normal and deaf mice showed persistent $\mathrm{Na}^{+}$currents after fast inactivation. Persistent current amplitudes (at $-15 \mathrm{mV}$ ) measured $3 \mathrm{~s}$ after the onset of the voltage step were $8 \pm 0.5 \%$ of the peak $\mathrm{Na}^{+}$ current in deaf mice neurons and $3.5 \pm 0.4 \%$ in normal mice neurons ( $n=8, P<0.03$; Fig. 2A). Persistent currents were TTX-sensitive (Fig. 2A, TTX-subtracted traces) and the amplitude of these currents decreased by lowering $\mathrm{Na}^{+}$concentration (see Supplementary material, Fig. S1). In low-Na ${ }^{+}$ACSF, persistent current amplitudes were similar to amplitudes in normal $\mathrm{Na}^{+}$ACSF $\left(8 \pm 1 \%\right.$ of the peak $\mathrm{Na}^{+}$ current in deaf mice and $3 \pm 1 \%$ in normal mice, $P<0.04)$. We also investigated TTX-sensitive resurgent $\mathrm{Na}^{+}$currents by applying a $0 \mathrm{mV}$ voltage step followed by steps varying from $-75 \mathrm{mV}$ to $-30 \mathrm{mV}$. There was no relationship between $\mathrm{Na}^{+}$conductance and $\mathrm{Na}^{+}$current half-width. The voltage dependence of persistent currents also appeared to be independent of the maximum $\mathrm{Na}^{+}$conductance (data not shown). Resurgent $\mathrm{Na}^{+}$currents also inactivated more slowly in deaf mice than in normal mice $(27 \pm 2$ vs. $15 \pm 2 \mathrm{~ms}$, respectively, $n=18, P<0.01$; Fig. $2 \mathrm{~B}$ and $\mathrm{C}$; measured at $-15 \mathrm{mV}$; resurgent 


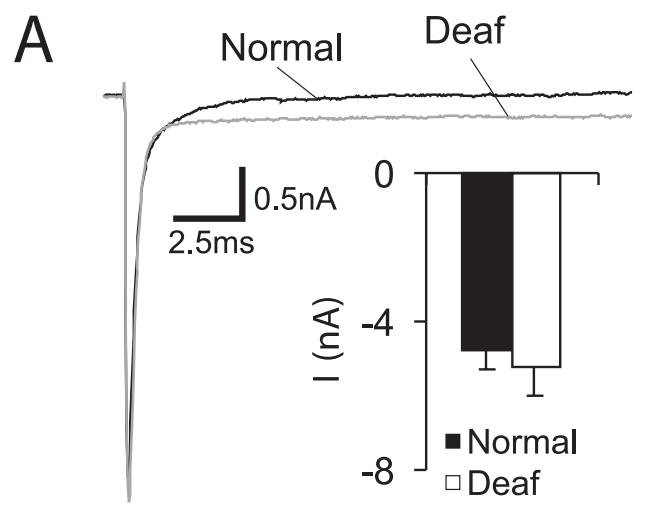

B
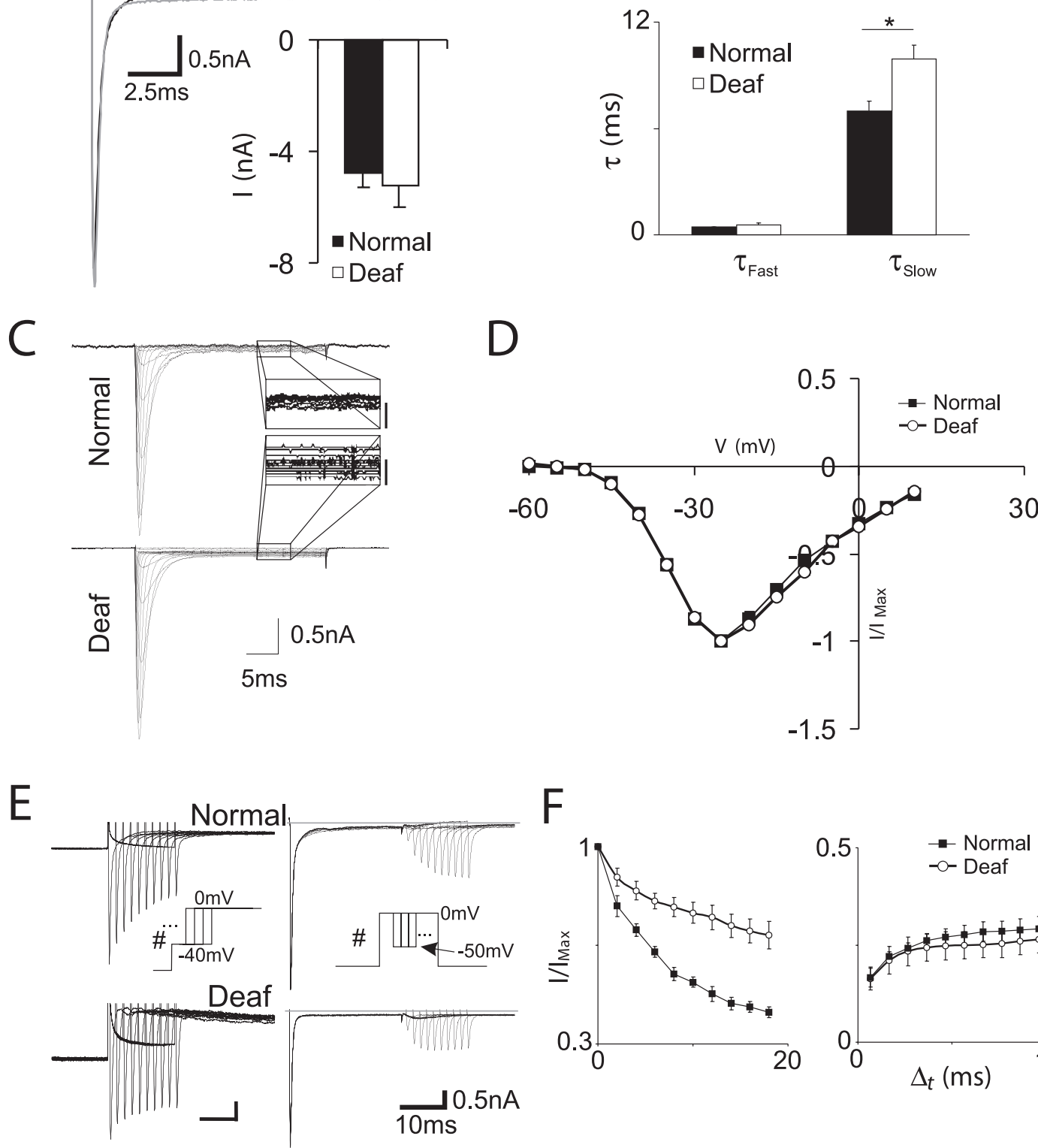
A
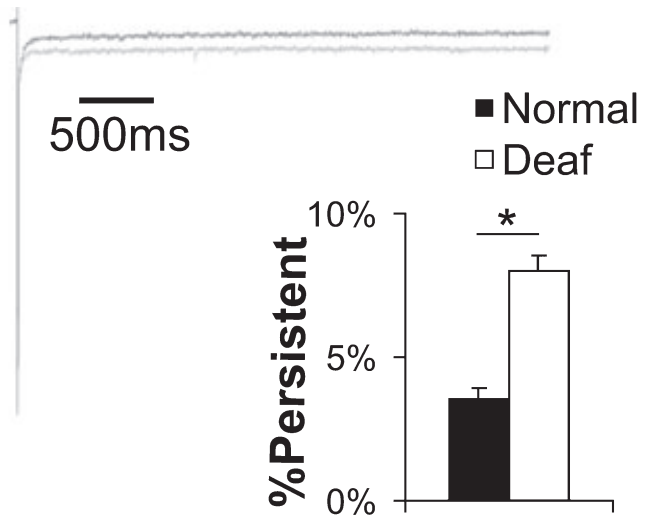

B
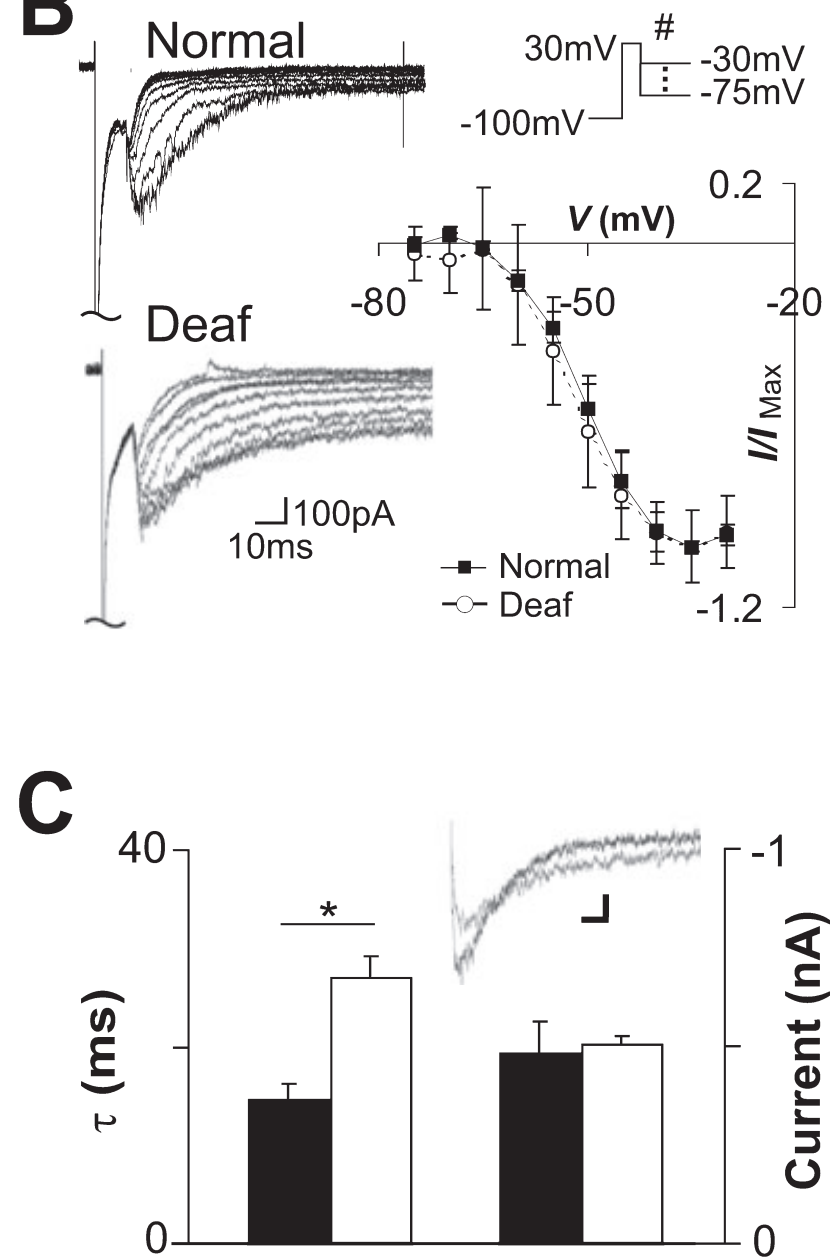

FIG. 2. $\mathrm{Na}^{+}$currents show greater persistent components in deaf mice MNTB neurons. (A) Example of two current traces elicited by a $-15-\mathrm{mV}$ voltage step (3 s long) from a normal (black trace) and a deaf (grey trace) mouse MNTB neuron. Inset: summary percentage of the persistent current (ratio between the current measured at $3 \mathrm{~s}$ and peak current). (B) Left: representative examples of resurgent $\mathrm{Na}^{+}$currents from a normal (top) and a deaf (bottom) mouse. Right: summary I-V relationships (normalized resurgent currents - peak amplitude - vs. step voltage) from normal (filled boxes - thin line) and deaf (open circles - thick line) mice MNTB neurons (means \pm SEM). The protocols used to elicit resurgent currents are detailed in the text and shown (\#). (C) Summary of resurgent currents inactivation time constants (left bars) and peak amplitude (right bars) of normal (black bars) and deaf (white bars) mice neurons. Inset: resurgent $\mathrm{Na}^{+}$currents from a normal (black trace) and a deaf (grey trace) mouse observed at $-30 \mathrm{mV}$. mice. Moreover, inactivation time constants of resurgent currents were measured by fitting a single exponential function after baselining the traces at the end of the test pulse. This procedure is therefore likely to eliminate any persistent component from the exponential fitting.

\section{Normal and deaf mice $\mathrm{Na}^{+}$currents are similar at $P 7$}

Voltage-clamp recordings from $\mathrm{P} 7$ normal and deaf mice showed that the TTX-sensitive transient $\mathrm{Na}^{+}$current in MNTB neurons displayed larger amplitudes than the current observed in P14 mice. At P7, $\mathrm{Na}^{+}$ peak current in normal mice (Fig. 3A) was $-6.1 \pm 0.9 \mathrm{nA}(P=0.04$ compared with P14 normal mice currents; $n=24)$ and $-6.2 \pm 0.6 \mathrm{nA}$ in deaf mice $(P=0.04$ compared with $\mathrm{P} 14$ deaf mice currents; $n=24)$. No statistical difference was observed in peak $\mathrm{Na}^{+}$currents between normal and deaf mice. Fast inactivation time constants were significantly lower in P7 mice cells (both normal and deaf) than in normal P14 mice (Fig. 3B); fast inactivation time constants in P7 normal and deaf mice were both equal to $0.6 \pm 0.02 \mathrm{~ms}$ (Fig. $3 \mathrm{~B}$ ), whereas, at $\mathrm{P} 14$, the mean fast inactivation time constant was equal to $0.4 \pm 0.02 \mathrm{~ms}$ (Fig. 3B), significantly faster than both groups at P7 $(P<0.01$ compared with $\mathrm{P} 14$ normal mice in both cases). Interestingly, $\mathrm{Na}^{+}$currents in both normal and deaf P7 mice did not show either persistent or resurgent currents (Fig. 3C).

\section{Simulated deaf Nav channels improve high-frequency firing in normal neurons}

We used a dynamic clamp to assess the functional impact of slower persistent/resurgent $\mathrm{Na}^{+}$currents in MNTB neurons. We modelled the resurgent component of deaf mice $\mathrm{Na}^{+}$currents and simulated this component in normal MNTB neurons using a dynamic clamp. When digitally added to normal mice resurgent and transient $\mathrm{Na}^{+}$currents, the simulated $\mathrm{Na}^{+}$current component caused $\mathrm{Na}^{+}$currents in normal mice to resemble deaf mice $\mathrm{Na}^{+}$currents (Fig. 4A). In current clamp, injection of $200 \mathrm{pA}$ steps caused normal MNTB neurons to fire one or two APs (Leao et al., 2004; Fig. 4B). When simulated $\mathrm{Na}^{+}$currents are injected to normal mice neurons, the firing frequency remains the same; however, the AP on the step reaches its peak earlier than when no simulated current is present $(4.3 \pm 0.3$ vs. $4.7 \pm 0.5 \mathrm{~ms}$, respectively; $n=9, P=0.05$, paired $t$-test; Fig. 4B and D). Trains of current pulses (20 pulses, $2 \mathrm{nA}, 200$ or $300 \mathrm{~Hz}$ ) were also injected into normal mice MNTB neurons with and without simulated $\mathrm{Na}^{+}$currents. In control conditions, for $300 \mathrm{~Hz}$ stimulation, normal mice MNTB neurons responded with APs in $16 \pm 2$ pulses whereas, if simulated currents were injected, the cells fired $19.8 \pm 0.2$ APs $(n=9, P=0.04$, paired $t$-test; Fig. 4C). Deaf mice MNTB neurons also fired more APs in response to the current pulses compared with normal mice with no simulated current $(19.9 \pm 0.1$ APs; $n=18, P=0.04$; Fig. 4C). In control conditions, when stimulated with $200-\mathrm{Hz}$ current pulses, AP amplitudes in MNTB neurons tend to decrease after each pulse, reflecting the development of inactivation of transient $\mathrm{Na}^{+}$currents (Fig. 4C and D). The ratio between the last (20th) AP amplitude vs. the 1 st AP amplitude in normal mice (control) was equal to $0.91 \pm 0.01$. However, if the simulated $\mathrm{Na}^{+}$currents were incorporated to the membrane, this ratio increased to $0.94 \pm 0.01(n=9, P<0.05$, paired $t$-test); similar ratios were observed in neurons of deaf mice $(0.93 \pm 0.01, P=0.05$ compared with normal mice ratios without the dynamic clamp; Fig. 4D). Because resurgent currents are known to promote high-frequency firing in cerebellar Purkinje neurons (Raman $\&$ Bean, 2001), we assessed the role of the abnormal $\mathrm{Na}^{+}$currents when 


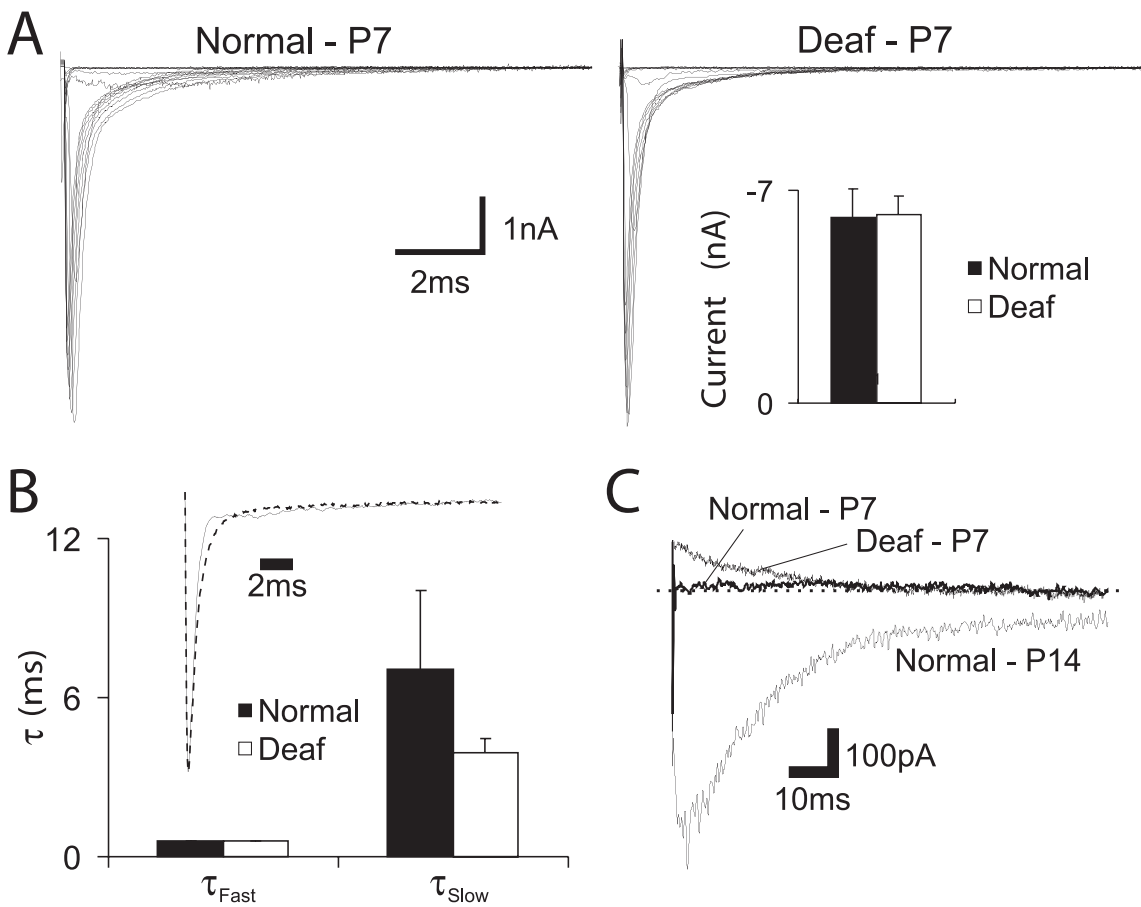

FIG. 3. Postsynaptic MNTB $\mathrm{Na}^{+}$currents in younger animals are similar in normal and deaf mice.

(A) Examples of TTX-sensitive $\mathrm{Na}^{+}$currents recorded at several potentials from a normal (left traces) and a deaf (right traces) young (P7) mouse MNTB neuron. Inset: summary (means \pm SEM) of maximum TTXsensitive $\mathrm{Na}^{+}$currents in $\mathrm{P} 7$ normal (black bars) and deaf (white bars) mice. (B) Summary of inactivation time constants (means \pm SEM) of normal (black bars) and deaf (white bars) P7 mice (for currents recorded at $-15 \mathrm{mV}$ ). Inset: $\mathrm{Na}^{+}$currents from a normal P14 (solid line) and a normal P7 (dashed line) mouse overlaid. (C) Examples of overlaid TTX-sensitive currents elicited by a $-30 \mathrm{mV}$ voltage step (after a $0 \mathrm{mV}$ step) used to record resurgent currents. normal mice MNTB neurons acquire the multiple firing phenotype observed in deaf mice MNTB neurons (Leao et al., 2004). We applied $20 \mathrm{nM}$ of dendrotoxin-I (DTX) to normal mice MNTB neurons partially to block low-threshold voltage-dependent $\mathrm{K}^{+}$currents in order to resemble the proposed altered Kv1-mediated currents in deaf mice (Leao et al., 2004). In the presence of DTX, a $200 \mathrm{~ms}$ current step of $200 \mathrm{pA}$ caused cells to fire $5 \pm 2.2$ APs, whereas if the simulated $\mathrm{Na}^{+}$ currents were applied to the cell, the number of APs increased to $7.25 \pm 2.4(n=6, P<0.02$, paired $t$-test; Fig. 4D and E). The amplitude ratio between the last and the first AP in the step, however, was significantly smaller after simulated currents were injected $(0.69 \pm 0.05$ without the dynamic clamp and $0.47 \pm 0.06$ with the dynamic clamp, $n=6, P=0.04$, paired $t$-test; Fig. $4 \mathrm{E}$ ).

\section{Nav1.6 is expressed in MNTB neurons from P14 deaf mice}

We carried out immunolabelling using antibodies anti-Nav1.6; this channel subtype is known to be responsible for non-inactivating and resurgent $\mathrm{Na}^{+}$currents in other systems (Maurice et al., 2001; Raman \& Bean, 2001). Nav1.6 proteins were not observed in MNTB sections from P14 normal mice (OD $<0.01, n=4$; Fig. 5A), whereas strong Nav1.6 labelling $(\mathrm{OD}=0.35 \pm 0.01, n=4, P<0.01)$ was observed in MNTB sections of P14 deaf mice (Fig. 5B). Nav1.6 labelling is likely to be pre- and postsynaptic (see Supplementary material, Fig. S1). As Nav1.1 and 1.2 are known to be present in cell bodies of brainstem neurons, we investigated the presence of these two $\mathrm{Na}^{+}$ channel subtypes using immunohistochemistry (Novakovic et al., 2001). At P14, Nav1.1 gene transcripts are expressed in MNTB principal cells in normal and deaf mice (Fig. 5C). No apparent Nav1.2 labelling was observed in normal or deaf mice MNTB.

\section{Young normal and deaf mice show Nav1.6 in MNTB neurons}

Nav1.1 was present in both normal and deaf mice MNTB in all age groups (P14, Fig. 5A and B; P7 and P28, Fig. 5C). Nav1.6 labelling was observed in the younger group (P7) in both normal $(\mathrm{OD}=0.26 \pm 0.03, n=4)$ and deaf mice $(\mathrm{OD}=0.32 \pm 0.04$, $n=4$, n.s.). However, in normal mice, no Nav1.6 labelling was observed in cell bodies of the P14 or P28 age groups $(\mathrm{OD}<0.01$, $n=4$; Fig. 5C). Nevertheless, Nav1.6 labelling was observed in all deaf age groups $(\mathrm{OD}=0.3 \pm 0.02, n=4, \quad$ for $\mathrm{P} 7$ and $\mathrm{OD}=0.26 \pm 0.03, n=4$, for P28, $P<0.01$ in both cases when compared with normal mice sections from the same age group; Fig. 5C).

\section{Discussion}

We have studied TTX-sensitive $\mathrm{Na}^{+}$currents in postsynaptic MNTB neurons of normal and congenitally deaf mice. Our electrophysiological results are likely to represent mostly somatic $\mathrm{Na}^{+}$currents as the technique of lifting the neuron removes large processes (observed by filling cells with Alexa-488). However, it is likely that initial segments of dendrites and axons are also present in the preparation. The disruption of dendrites also caused a significant drop in cell capacitance (for comparisons, see Leao et al., 2005b). Our results differ from the work of Leao and others as these authors have found little or no voltage-gated $\mathrm{Na}^{+}$currents in patches pulled from rat MNTB neurons (Leao et al., 2005b). These differences may arise from species variability or because most of the $\mathrm{Na}^{+}$currents described here are generated in initial segments of dendrites and axons (we found, however, a significant amount of $\mathrm{Na}^{+}$currents in patches pulled possibly from MNTB somas - see Supplementary material, Fig. S1). Unpublished data from Leao indicate that initial dendritic compartments may be 'rich' in Nav channels. We cannot speculate precisely whether the currents recorded in this study are purely somatic or axonal/dendritic; however, independent of the specific location of $\mathrm{Na}^{+}$ channels in mice MNTB neurons, the currents shown here can be considered, in electrotonic terms, to be somatic. In other words, these channels are likely to be expressed in regions that are isopotential in comparison with the soma. Our findings show that, 
FIG. 4. Incorporating a 'deaf'-like $\mathrm{Na}^{+}$current in normal mice neurons improves the cell's ability to fire at high frequencies. (A) Traces showing transient and resurgent currents in normal mice (solid black trace), in deaf mice (grey trace) and in normal mice when our simulated 'deaf' mice current model used in our dynamic clamp experiments was digitally added (dotted traces). (B) Voltage traces in normal mice MNTB cell elicited by a 200 pA current step without (solid line) and with (dashed line) the simulated current (inset: an expanded view of the shaded area). (C) APs elicited by short current pulses $(200 \mathrm{~Hz})$ in a normal mouse MNTB neuron (left), the same neuron with the simulated current (centre) and a deaf mouse MNTB neuron (left). (D) Summaries of (data points obtained from the same cells are connected by thin lines): (1) AP delays in normal mice MNTB neurons without (ND - left circles) and with (D - right circles) the dynamic clamp. Horizontal lines represent mean responses; (2) left: last vs. first AP amplitude ratios in normal mice without the dynamic clamp (ND) and normal mice with the dynamic clamp (D) in response to $200 \mathrm{~Hz}$ current pulses; right: ratios of APs to number of pulses in a $300 \mathrm{~Hz}$ pulse stimulation (stim/AP) in normal mice without dynamic clamp (ND) and normal mice with the dynamic clamp (D); ${ }^{* *} P \leq 0.05$, paired $t$-test. Panel 2 shows data in terms of means and \pm SEM error bars in order to improve the clarity of the graph. Dark grey lines and light grey boxes represent the mean and \pm SEM values, respectively, for deaf mice ( $y$-axis values are the same for the left and right panels, please note that this axis shows values from 0.5 to 1 ); ${ }^{*} P \leq 0.05$, unpaired $t$-test comparing means of normal and deaf mice; $\# P \leq 0.05$, paired $t$-test comparing means of normal mice without and with dynamic clamp. (E) Left: membrane response of a normal mouse MNTB neuron in the presence of $20 \mathrm{nM}$ DTX-I without (solid line) and with (dashed line) dynamic clamp. Right: AP count observed in normal mice MNTB neurons in the presence of $20 \mathrm{nM}$ DTX-I without (ND) and with dynamic clamp (D); grey lines represent the mean AP count for the two conditions; ${ }^{* *} P \leq 0.05$, paired $t$-test.
A

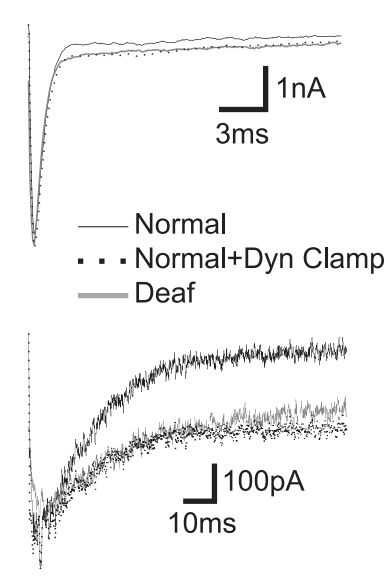

B

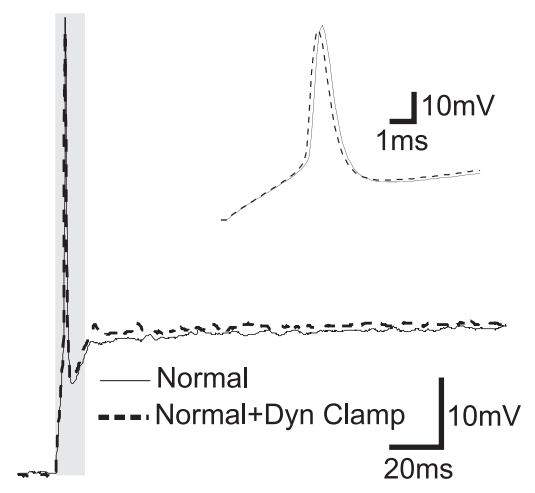

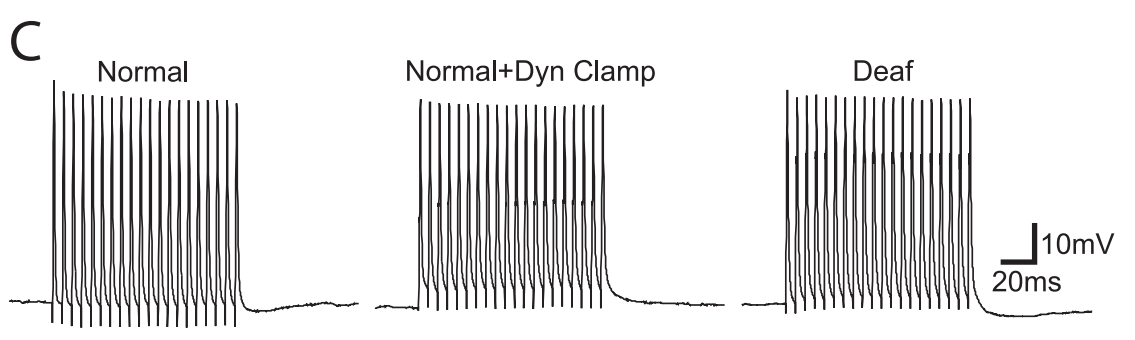
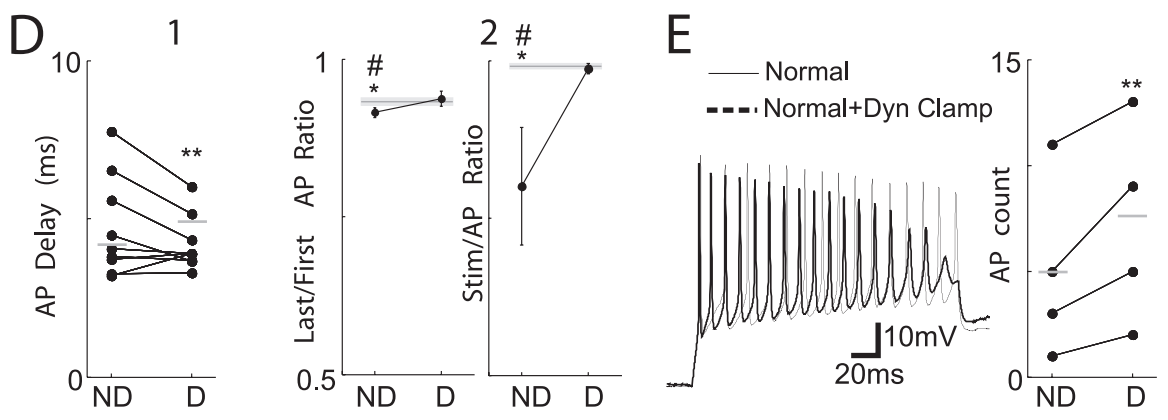

in deaf mice, both transient and resurgent $\mathrm{Na}^{+}$currents are altered. The amount of persistent $\mathrm{Na}^{+}$current after fast $\mathrm{Na}^{+}$channel inactivation elicited by short voltage steps was increased in deaf mice and resurgent $\mathrm{Na}^{+}$currents showed slower inactivation in deaf mice as compared with control mice. It is known that a poor space-clamp can produce erroneous persistent currents associated with non-uniform potentials across cell regions with high axial resistance (White et al., 1995). Incorrect space-clamp is particularly problematic in recording of sodium currents owing to high conductances, fast kinetics and nonuniform distribution in neurons (White et al., 1995). However, the simple morphology of MNTB cells and the disruption of neuronal processes through lifting the neurons from the slice and the use of lowsodium extracellular recording solution minimize errors related to nonuniform distribution of voltage-clamp pulses. Moreover, we did not observe any relationship between $\mathrm{Na}^{+}$conductance and current halfwidth or the ratio between peak and steady-state current (White et al., 1995). In this study, we did not assess whether $\mathrm{Na}^{+}$currents were altered in calyceal terminals of deaf mice MNTB. However, it is likely that $\mathrm{Na}^{+}$currents in terminals may not be altered, as the synaptic properties of presynaptic terminals and the presynaptic cells are not changed by congenital deafness (Oleskevich et al., 2004; Leao et al., 2005b; Youssoufian et al., 2005).

Our immunohistochemical studies revealed that, at P14, there is a striking difference in the expression of $\mathrm{Na}^{+}$channel subunits. While
Nav1.1 proteins are present in both normal and deaf mice, postsynaptic Nav1.6 expression was only observed in deaf mice MNTB neurons. In the mammalian central nervous system, isoforms of sodium channels are distinctly localized during different stages of development. For example, Nav1.1 is detectable soon after birth and increases through adulthood. Nav1.2 is detectable at embryonic stages and also increases through adulthood (Novakovic et al., 2001). Nav1.6 peaks during embryonic and postnatal periods but remains detectable through adulthood (Novakovic et al., 2001). Nav1.2 channels tend to be more expressed rostrally and the larger expression of Nav1.1 is caudal (Novakovic et al., 2001). In adults, at subcellular levels, Nav1.1 channels are mostly localized in cell bodies, Nav1.2 in neurites and Nav1.6 in nodes of Ranvier. However, early in development, Nav1.2 is highly expressed in cell bodies and also in nodes of Ranvier and unmyelinated axons whereas Nav1.6 proteins are present in cell bodies, but these channels tend to migrate to nodes of Ranvier (Novakovic et al., 2001; Ogata \& Ohishi, 2002; Herzog et al., 2003). The migration of Nav1.6 to nodes of Ranvier is one of the factors responsible for generating fast APs that recover quickly from inactivation (Novakovic et al., 2001; Ogata \& Ohishi, 2002; Herzog et al., 2003). We have not found Nav1.2 staining in either normal or deaf mice. These results are in agreement with a previous immunohistochemical study in the rat showing no expression of Nav1.2 in rat MNTB (Leao et al., 2005a). Our results also imply that most of the 

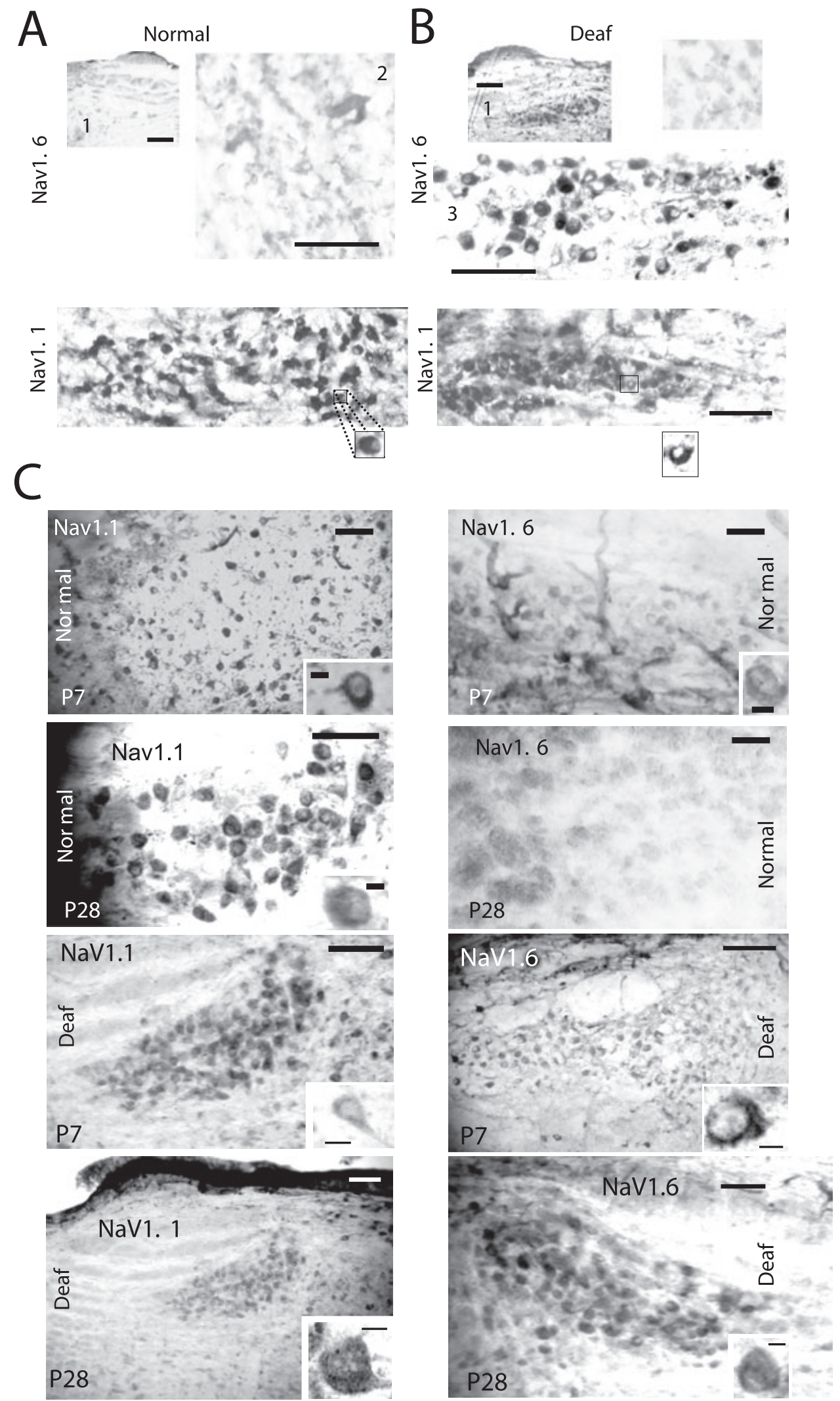

FIG. 5. Nav1.6 is abnormally expressed in deaf mice neurons. (A) Photomicrographs of a normal mouse MNTB labelled with Nav1.6 antibodies: left, low-

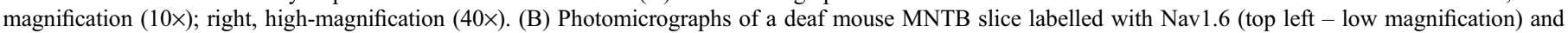
another slice to which Nav1.6 antibodies were applied with its control peptide (top right - negative control; high magnification); bottom, high-magnification (40×) of a deaf mouse MNTB and Nav1.6 antibodies. (C) Left: representative examples of Nav1.1 labelling of a normal (top) and a deaf mouse MNTB slice (scale bars, $100 \mu \mathrm{m})$. Right: immunohistochemistry of Nav1.1 and Nav1.6 proteins in younger (P7) and older (P28) normal and deaf mice MNTB slices. 
postsynaptic $\mathrm{Na}^{+}$currents recorded from older normal mice arise from $\mathrm{Na}^{+}$channels containing Nav1.1 subunits. It is likely that early in development, MNTB neurons express Nav1.6 in cell somas and the subcellular displacement of these channels to other cellular domains occurring later in life is modulated by activity. Our data indicate that in both normal and deaf mice, Nav1.6 is expressed in cell somas and probably at initial segments of dendrites and axons during early developmental stages but these channels only remain present in deaf mice MNTB neurons (at the soma or at compartments in the somatic vicinity) later in development. As there was also strong cytoplasmic labelling of Nav1.6 in deaf mice, it is likely that Nav1.6 proteins are being synthesized at the soma to populate the soma membrane at other subcellular locations (e.g. axon and/or dendrite). The detection of Nav1.6 proteins in cell bodies of both normal and deaf mice at younger ages indicates that these channels might also migrate from the cell soma to other subcellular compartments and this migration is modulated by activity. We cannot at present speculate if Nav1.6 trafficking to axonal domains is disrupted in deaf mice.

Abnormal activity is known to alter the expression of different Nav subunits. In an animal model of epilepsy, for example, Nav1.1 and Nav1.6 but not Nav1.2 are up-regulated in somatosensory neurons (Klein et al., 2004). Other factors, such as glial cell interactions with MNTB neurons, could also contribute to the abnormal expression of Nav1.6 channels. It is known that Nav1.6 expression at nodes of Ranvier requires proper development of paranodal axoglial junctions (Suzuki et al., 2004). However, the normal morphological and functional development of the calyx of Held argues against the idea of an important alteration of non-neural structures in deaf mice MNTB (Youssoufian et al., 2005).

Nav1.6 has been associated with the expression of resurgent current in Purkinje neurons and this current is considerably reduced in these neurons from Nav1.6 knockout mice. However, the same knockout mouse displayed a $\mathrm{Na}^{+}$resurgent current in other neurons (Do \& Bean, 2004). Grieco \& Raman (2004) showed that neurons with initially no resurgent current could produce such a current when the inactivation of transient currents was slowed by $\beta$-pompilodotoxin. These results suggested that resurgent currents were not solely produced by the Nav1.6 $\alpha$ subunit but from other factors. However, lower inactivation time constants (attributed to the Nav1.6 $\alpha$ subunit) contributed to the presence of the resurgent current. Raman \& Bean (2001) showed that in order for the resurgent current to occur, $\mathrm{Na}^{+}$channels undergo two types of inactivation: the classical channel closing and a second through an open state block (i.e. by $\mathrm{Mg}^{2+}$ ). Once the membrane repolarizes (even for short periods), the blocked open channels become unblocked allowing the passage of $\mathrm{Na}^{+}$ions. Grieco et al. (2005) have shown that auxiliary $\beta_{4}$ subunits may, in fact, be responsible for blocking the channel and therefore promoting the resurgent $\mathrm{Na}^{+}$current. Interestingly, both normal and deaf mice displayed resurgent currents; however, they inactivated considerably more slowly in deaf mice neurons. The lack of expression of Nav1.6 subunits suggests that other $\mathrm{Na}^{+}$channel $\alpha$ subunits are able to pass resurgent current by interacting with the putative blocking particle likely to be present in both normal and deaf mice (Do \& Bean, 2004). Unfortunately, there is no commercially available anti- $\beta_{4}$ antibody to test the hypothesis that this accessory $\mathrm{Na}^{+}$channel subunit is present in both normal and deaf mice neurons. Rates of inactivation of different $\alpha$ subunits largely depend on the cell type in which they are expressed and it is currently accepted that resurgent currents are related to the inactivation rate of $\mathrm{Na}^{+}$channels. In other words, in order for a resurgent current to occur it is necessary to have a relatively slow inactivation of an $\alpha$ subunit, and a functional blocking particle. Although Nav1.6 subunits were not necessary for the production of resurgent currents in normal mice, these subunits may be associated with the larger persistent $\mathrm{Na}^{+}$currents and slower inactivation kinetics of resurgent currents observed in P14 deaf mice. Nav1.6 subunits have been associated with persistent $\mathrm{Na}^{+}$currents in other systems (Rush et al., 2005). The absence of both persistent and resurgent currents in younger animals (P7) despite the presence of Nav1.6 subunits indicates again that other factors (e.g. accessory subunits) may trigger the appearance of these currents later in development. Moreover, the current phenotype of an Nav channel containing a given subunit can be modulated by development (Pineda et al., 2005). The presence of postsynaptic persistent currents in MNTB neurons from normal mice is in agreement with the results from Leao et al. (2005a); however, the differences in persistent current amplitudes (greater in their results) might arise from species variability.

The existence of slower inactivating $\mathrm{Na}^{+}$currents in normal mice MNTB neurons does not seem to cause abnormal responses to highfrequency stimulation (as demonstrated by our dynamic clamp experiments), but when low-threshold voltage-dependent $\mathrm{K}^{+}$currents were partially blocked by DTX, $\mathrm{Na}^{+}$channels demonstrated a greater accumulation of inactivation. The presence of persistent/resurgent currents may in some cases be beneficial (e.g. high-frequency firing; Fig. 4) when low-threshold voltage-dependent $\mathrm{K}^{+}$channels were intact. In Purkinje neurons, resurgent currents are important for highfrequency firing, and Nav1.6 knockout mice display reduced excitability (Khaliq et al., 2003). However, resurgent currents also contribute to spontaneous activity, a feature that would be undesirable for MNTB neurons (Khaliq et al., 2003). Moreover, the favourable effect caused by the altered expression of $\mathrm{Na}^{+}$currents in deaf mice for short-duration pulses could impair the cell response for sustained depolarization. As shown in Fig. 4E, despite the increased number of APs in a current step (after the partial block of low-threshold voltagedependent $\mathrm{K}^{+}$currents), normal mice neurons displayed a greater accumulation of inactivation when simulated deaf mice $\mathrm{Na}^{+}$currents were added to the neuron (under the presence of DTX). These results suggest that 'competent' low-threshold voltage-dependent $\mathrm{K}^{+}$currents are necessary to allow $\mathrm{Na}^{+}$channels to recover quickly from inactivation. The interaction between $\mathrm{K}^{+}$currents and recovery of $\mathrm{Na}^{+}$channels from inactivation has been previously shown (Raman \& Bean, 1999). In normal MNTB neurons, the requirement of slowly inactivating resurgent currents may not be necessary as strong lowthreshold voltage-dependent $\mathrm{K}^{+}$currents may prevent development of inactivation. Additionally, strong calyceal currents would easily trigger APs initiated in other subcellular domains without the need for somatic $\mathrm{Na}^{+}$currents (i.e. initial segments of axons). Moreover, non-inactivating $\mathrm{Na}^{+}$currents could cause $\mathrm{Na}^{+}$accumulation at the soma after prolonged AP firing, increasing the energy expense of highfrequency firing and decreasing the ability of the postsynaptic neuron to phase-lock to its input.

This study shows that the expression of Nav channels in MNTB neurons is regulated both by development and by activity, and the postsynaptic $\mathrm{Na}^{+}$channels do not show the particular characteristics (e.g. extremely fast recovery from inactivation) of presynaptic channels. We have also demonstrated that developmental changes in the $\mathrm{Na}^{+}$channel subunit are disrupted by congenital deafness. The persistence of Nav1.6 subunits could cause cell degeneration and impair phase-locking of MNTB neurons by increasing use-dependent inactivation after prolonged AP firing (Fig. 4E). The presence of Nav1.6 at normal mice somas at young ages followed by the disappearance of this subunit in older developmental stages suggest the migration of this channel type to other cellular domains (e.g. nodes of Ranvier). This migration could be essential to the way that MNTB neurons respond to calyceal inputs. High-frequency firing has been 
extensively reported in calyx of Held studies (for a review see Taschenberger et al., 2002). However, it is not known if MNTB neurons (and their axons) are able to follow high-frequency arising from the calyx. Future studies should address the properties of Nav channels of MNTB axons. MNTB neurons can receive strong EPSCs at astonishing frequencies; however, their ability to follow highfrequency inputs is closely related to the properties of postsynaptic Nav channels.

\section{Supplementary material}

The following supplementary material may be found on

http://www.blackwell-synergy.com

Fig. S1. An example of the effect of low external $\mathrm{Na}+$ concentration on the amplitude of the persistent $\mathrm{Na}+$ currents in deaf mice.

\section{Acknowledgements}

We would like to thank Drs I. M. Raman and F. R. Edwards for helpful comments on the manuscript.

\section{Abbreviations}

AOI, area of interest; AP, action potential; DTX, dendrotoxin; EPSC, excitatory postsynaptic current; MNTB, medial nucleus of the trapezoid body; OD, optical density; PBS-T, PBS plus Triton; P, postnatal day; TTX, tetrodotoxin.

\section{References}

Brew, H.M. \& Forsythe, I.D. (2005) Systematic variations of potassium current amplitudes across the tonotopic axis of the rat medial nucleus of the trapezoid body. Hear. Res., 206, 116-132.

Carner, M.J., Lo A.C., Black, J.A. \& Waxman, S.G. (2003) Abnormal sodium channel distribution in optic nerve axons in a model of inflamatory demyelination. Brain, 126, 1552-1561.

Do, M.T. \& Bean, B.P. (2004) Sodium currents in subthalamic nucleus neurons from Nav1.6-null mice. J. Neurophysiol., 92, 726-733.

Grieco, T.M., Afshari, F.S. \& Raman, I.M. (2002) A role for phosphorylation in the maintenance of resurgent sodium current in cerebellar purkinje neurons. J. Neurosci., 22, 3100-3107.

Grieco, T.M., Malhotra, J.D., Chen, C., Isom, L.L. \& Raman, I.M. (2005) Open-channel block by the cytoplasmic tail of sodium channel beta4 as a mechanism for resurgent sodium current. Neuron, 45, 233-244.

Grieco, T.M. \& Raman, I.M. (2004) Production of resurgent current in NaV1.6null Purkinje neurons by slowing sodium channel inactivation with betapompilidotoxin. J. Neurosci., 24, 35-42.

von Hehn, C.A.A., Bhattacharjee, A. \& Kaczmarek, L.K. (2004) Loss of Kv3.1 tonotopicity and alterations in cAMP response element-binding protein signalling in central auditory neurons of hearing impaired mice. J. Neurosci., 24, 1936-1940.

Herzog, R.I., Liu,C., Waxman, S.G. \& Cummins, T.R. (2003) Calmodulin binds to the $\mathrm{C}$ terminus of sodium channels Nav1.4 and Nav1.6 and differentially modulates their functional properties. J. Neurosci., 23, 8261-8270

Keats, B.J., Nouri, N., Huang, J.M., Money, M., Webster, D.B. \& Berlin, C.I. (1995) The deafness locus (dn) maps to mouse chromosome 19. Mann. Genome, 6, 8-10.

Khaliq, Z.M., Gouwens, N.W. \& Raman, I.M. (2003) The contribution of resurgent sodium current to high-frequency firing in Purkinje neurons: an experimental and modeling study. J. Neurosci., 23, 4899-4912.

Klein, J.P., Khera, D.S., Nersesyan, H., Kimchi, E.Y., Waxman, S.G. \& Blumenfeld, H. (2004) Dysregulation of sodium channel expression in cortical neurons in a rodent model of absence epilepsy. Brain Res., 1000, $102-109$.

Leao, R.N., Berntson, A., Forsythe, I.D. \& Walmsley, B. (2004) Reduced lowvoltage activated $\mathrm{K}^{+}$conductances and enhanced central excitability in a congenitally deaf $(d n / d n)$ mouse. J. Physiol., 559, 25-33.

Leao, R.M., Kushmerick, C., Pinaud, R., Renden, R., Li, G.L., Taschenberger, H., Spirou, G., Levinson, S.R. \& von Gersdorff, H. (2005a) Presynaptic $\mathrm{Na}^{+}$ channels: locus, development, and recovery from inactivation at a highfidelity synapse. J. Neurosci., 25, 3724-3738.

Leao, R.N., Svahn, K., Berntson, A. \& Walmsley, B. (2005b) Hyperpolarization-activated (I) currents in auditory brainstem neurons of normal and congenitally deaf mice. Eur. J. Neurosci., 22, 147-157.

Leao, R.N., Sun, H., Svahn, K., Bertson, A., Youssufian, M., Paolini, A.G., Fyffe, R.E. \& Walmsley, B. (2006) Topographic organisation in the auditory brainstem of juvenile mice is distributed in congential deafness. J.Physiol., 571, 563-78.

Maurice, N., Tkatch, T., Meisler, M., Sprunger, L.K. \& Surmeier, D.J. (2001) D1/D5 dopamine receptor activation differentially modulates rapidly inactivating and persistent sodium currents in prefrontal cortex pyramidal neurons. J. Neurosci., 21, 2268-2277.

Ming, G. \& Wang, L.Y. (2003) Properties of voltage-gated sodium channels in developing auditory neurons of the mouse in vitro. Chin. Med. Sci. J., 18, $67-74$.

Novakovic, S.D., Eglen, R.M. \& Hunter, J.C. (2001) Regulation of $\mathrm{Na}^{+}$ cahnnel distribution in the nervous system. Trends Neurosci., 24, 473-478.

Ogata, N. \& Ohishi, Y. (2002) Molecular diversity of structure and function of voltage-gated $\mathrm{Na}^{+}$channels. J. Pharmacol., 88, 365-377.

Oleskevich, S., Youssoufian, M. \& Walmsley, B. (2004) Presynaptic plasticity at two giant auditory synapses in normal and deaf mice. J. Physiol., 560, 709-719.

Pertin, M., Ji, R.R., Berta, T., Powell, A.J., Karchewski, L., Tate, S.N., Isom, L.L., Woolf, C.J., Gilliard, N., Spahn, D.R. \& Decosterd, I. (2005) Upregulation of the voltage-gated sodium channel beta2 subunit in neuropathic pain models: characterization of expression in injured and non-injured primary sensory neurons. J. Neurosci., 25, 10970-10980.

Pineda, R.H., Heiser, R.A. \& Ribera, A.B. (2005) Developmental, molecular, and genetic dissection of $\mathrm{INa}$ in vivo in embryonic zebrafish sensory neurons. J. Neurophysiol., 93, 3582-3593.

Raman, I.M. \& Bean, B.P. (1999) Ionic currents underlying spontaneous action potentials in isolated cerebellar Purkinje neurons. J. Neurosci., 19, 16631674.

Raman, I.M. \& Bean, B.P. (2001) Inactivation and recovery of sodium currents in cerebellar Purkinje neurons: evidence for two mechanisms. Biophys. J., 80, 729-737.

Rasband, N.M., Kagawa, T., Park, W.E., Ikenaka, K. \& Trimmer, S.J. (2003) Dysregulation of axonal sodium channel isoforms after adult-onset chronic demyelination. J. Neurosci. Res., 73, 465-470.

Rush, A.M., Dib-Hajj, S.D. \& Waxman, S.G. (2005) Electrophysiological properties of two axonal sodium channels, Nav1.2 and Nav1.6, expressed in mouse spinal sensory neurones. J. Physiol., 564, 803-815.

Smith, M.R., Smith, R.D., Plummer, N.W., Meisler, M.H. \& Goldin, A.L. $(1998)$ Functional analysis of the mouse Scn8a sodium channel. J.Neurosci., 18, 6093-6102.

Suzuki, A., Hohi, T., Ishibashi, T., Hayashi, A., Yamaguchi, Y. \& Baba, H. (2004) Paranodal axoglial junction is required for the maintenance of the Nav1.6-type sodium channel in the node of Ranvier in the optic nerves but not in peripheral nerve fibers in the sulfatide-deficient mice. Glia, 46, 274-283.

Taschenberger, H., Leao, R.M., Rowland, K.C., Spirou, G.A. \& von Gersdorff, H. (2002) Optimizing synaptic architecture and efficiency for high-frequency transmission. Neuron., 36, 1127-1143.

White, J.A., Sekar, N.S., Kay \& A.R. (1995) Errors in persistent inward currents generated by space-clamp errors: a modeling study. J. Neurophysiol., 73, 2369-2377.

Youssoufian, M., Oleskevich, S. \& Walmsley, B. (2005) Development of a robust central auditory synapse in congenital deafness. J. Neurophysiol., 94, $3168-3180$. 